\title{
Molecular transport behaviour of organic solvents through halloysite nanotubes filled ethylene-vinyl acetate copolymer
}

\author{
SUVENDU PADHI, P GANGA RAJU ACHARY and NIMAI C NAYAK* \\ Micro and Nano Materials Laboratory, Department of Chemistry, Institute of Technical Education and Research, \\ Siksha 'O’ Anusandhan University, Bhubaneswar, Odisha 751 030, India
}

MS received 31 October 2014; accepted 29 January 2015

\begin{abstract}
The transport behaviour of three organic solvents (benzene, toluene and xylene) through halloysite nanotubes (HNTs) filled ethylene-vinyl acetate (EVA) copolymer composites have been investigated in the temperature range 303-323 K. The effects of HNTs loading, nature of solvent and temperature on the transport behaviour of solvents through composites were studied. It has been observed that all the systems follow a Fickian mode of transport on increasing temperature. The solvent uptake and sorption coefficient decreases with the increase in halloysite loading while diffusion coefficients and permeation coefficients were found to be dependent on the concentration of filler. The percentage of bounds rubber content and swelling ratio decreases up to 7.5 phr filler content, whereas above $7.5 \mathrm{phr}$ filler loading were found to be increased due to poor dispersion of halloysite in EVA copolymer matrix. The transport behaviour of three organic solvents was further validated by their crosslink density values. The thermodynamic parameters such as enthalpy, entropy and free energy of sorption were evaluated. The positive values of free energy indicate the non-spontaneity of the sorption of HNTs filled EVA in aromatic solvents at $303 \mathrm{~K}$.
\end{abstract}

Keywords. Polymer nanocomposites; halloysite nanotubes; EVA; diffusion coefficient.

\section{Introduction}

Ethylene-vinyl acetate (EVA) copolymer is one of the important organic polymers, extensively used for electrical insulation, cable jacketing and repair, telecommunication cable manufacturing, component encapsulation and waterproofing, corrosion protection and packaging of components. However, pristine EVA copolymer does not often fulfill the requirements in terms of its thermal stability and mechanical properties in some specific areas. In recent years more attention has been given to the diffusion, sorption and permeation of solvents into elastomers as these basic phenomena play important roles in different areas of engineering and industry. The transport behaviour of various organic solvents and gases through polymers is of great technological importance and it plays a vital role in a variety of barrier applications. Thus the knowledge of the performance of polymers in the environment of hazardous solvents, vapours and temperature is essential for their successful applications as structural engineering materials. Hence, in the design and fabrication of barrier elastomeric materials for the transportation of liquids and gases, packaging of foodstuffs, solvent reservoirs, evaporators and controlled release devices, ${ }^{1-5}$ etc., is more important to carry out transport studies to eliminate the diffusion of chemicals into reinforced EVA copolymer products. This is necessary because the presence of these chemicals may affect the mechanical properties of the material, degrade the product that the reinforced EVA copolymer is to protect, damage the

*Author for correspondence (nimainayak@ soauniversity.ac.in) interface between the EVA copolymer and other material and pollute the environment. Hence, the present paper aims in understanding this aspect of sorption, diffusion and permeation process in EVA copolymer as it is critical to the development of reliable reinforced EVA copolymer products to be used in the recent environment.

The diffusion and transport properties of polymers were found to be strongly dependent on factors such as the nature of the polymer, the nature of the penetrant, crosslink density, temperature, etc. Another important factor is the nature of filler incorporated into the polymer matrix. Reinforcing fillers such as silica and carbon-based nanofillers have a significant role in the transport properties of an elastomer which further increases its mechanical durability, elastic properties and modifies the sorption and permeability to diffusants. The transport behaviour of the filler-elastomer systems depends on the filler size, surface area, state of aggregation, the amount of filler and the interaction between the filler and the matrix. The compatible inert fillers will take up the free volume within the polymer matrix and creates a tortuous path of the permeating molecules.

When the filler is incompatible with the polymer, voids tend to occur at the interface, which leads to an increase in free volume of the system and consequently permeability increases. Interaction of different fillers with the matrix can be understood from the studies of swelling and transport characteristics. Different researchers used the equilibrium swelling technique for finding out the interaction of different filler/fibres with polymers. For example the interaction of nanostructure-layered silicates filled natural rubber with 
natural rubber, carboxylated styrene butadiene rubber, and their blends by an equilibrium swelling method has been studied by Stephen et $a l .{ }^{6}$ George et $a l^{7}$ investigated the effect of different types of fillers such as cork, silica and carbon black on the transport of aromatic solvents in isotactic polypropylene/acrylonitrile-co-butadiene rubber blends.

Halloysite nanotubes (HNTs) are a kind of two-layered aluminosilicate clay $\left(\mathrm{Al}_{2} \mathrm{Si}_{2} \mathrm{O}_{5}(\mathrm{OH})_{4} \cdot 2 \mathrm{H}_{2} \mathrm{O}\right)$ with predominantly hollow micro and nanotubular structure chemically similar to kaolinite. The hollow micro and nanotubular structures ensure the high aspect ratio of HNTs, which gives a large amount of filler-polymer interaction as compared to other fillers. HNTs easily dispersed in a polymer matrix due to their unique crystal structure, low density of hydroxyl functional groups and their tubular shape.$^{8-10}$ The aim of the present work is to study the solvent transport properties of HNTs-filled EVA, using three aromatic hydrocarbons such as benzene, toluene and xylene at 303, 313 and $323 \mathrm{~K}$ temperature, respectively. More emphasis was given to the effect of filler loading, nature of fillers, polymer-filler interaction etc., on various transport properties such as diffusion coefficient, permeation coefficient and thermodynamic parameters.

\section{Experimental}

\subsection{Materials}

EVA copolymer with $45 \%$ vinyl acetate content (LEVAPREN 450), density $0.971 \mathrm{~g} \mathrm{ml}^{-1}$, and melt flow index $5 \mathrm{~g} \mathrm{~min}^{-1}$ was supplied by Lanxess, India. Dicumyl peroxide (DCP, 99\% pure) used as crosslinking agent was obtained from Hercules, India. Halloysite nanotube was purchased from Sigma-Aldrich, Germany. This material had an average tube diameter of $50 \mathrm{~nm}$ and inner lumen diameter of $15 \mathrm{~nm}$. The typical specific surface area of this halloysite was $65 \mathrm{~m}^{2} \mathrm{~g}^{-1}$; pore volume of $1.25 \mathrm{ml} \mathrm{g}^{-1}$; refractive index 1.54; and specific gravity $2.53 \mathrm{~g} \mathrm{~cm}^{-3}$. The solvents such as benzene, toluene and xylene reagent grade (99\%) were purchased from E. Merck (India) Ltd., Mumbai, India. The properties of the solvents are given in table 1 .

\subsection{Sample preparation}

The composite samples were synthesized by using solution mixing technique. Briefly, 10 parts of nanofillers were dispersed in 100 parts of toluene sonicated for $1 \mathrm{~h}$ and the

Table 1. Properties of solvents.

\begin{tabular}{lccccc}
\hline Solvent & $\begin{array}{c}\text { Molecular } \\
\text { mass volume } \\
\left(\mathrm{g} \mathrm{mol}^{-1}\right)\end{array}$ & $\begin{array}{c}\text { Density } \\
\left(\mathrm{g} \mathrm{cm}^{-3}\right)\end{array}$ & $\begin{array}{c}\text { Dipole } \\
\text { moment } \\
(D)\end{array}$ & $\begin{array}{c}\text { Boiling } \\
\text { point } \\
\left({ }^{\circ} \mathrm{C}\right)\end{array}$ & $\begin{array}{c}\text { Solubility } \\
\text { parameter } \\
(\mathrm{MPa})^{1 / 2}\end{array}$ \\
\hline Benzene & 78.11 & 0.879 & 0 & 79 & 18.7 \\
Toluene & 92.14 & 0.867 & 0.36 & 109 & 18.3 \\
Xylene & 106.17 & 0.865 & 0.70 & 137 & 18.2 \\
\hline
\end{tabular}

10 parts of EVA was dissolved in 100 parts of toluene at room temperature (RT) for $1 \mathrm{~h}$. Each suspension was added to the EVA solution and mixed again at RT for $1 \mathrm{~h}$. DCP $1.2 \mathrm{phr}$ as the curing agent was added to the rubber solution. After stirring in toluene, it was sonicated at room temperature for $0.5 \mathrm{~h}$. The final solution was cast over teflon trays and kept in air drying followed by vacuum drying at $50^{\circ} \mathrm{C}$, till there was practically no weight variation. The dried films were molded in a hot press at a pressure of $5 \mathrm{MPa}$ at $160^{\circ} \mathrm{C}$ for an optimum cure time, determined from a Monsanto oscillating disc rheometer (ODR, 100S). The formulation of the mixes is given in table 2 .

\subsection{Bound rubber content estimation}

The bound rubber content was determined by extracting the unbound materials such as ingredients and free rubbers. The bound rubber measurement was carried out at room temperature using toluene as solvent as the elastomer are easily dissolved in it. For the determination, approximately $1 \mathrm{~g}$ of uncured compound was cut into small pieces and placed into a stainless-steel wire-mesh cage of a known weight. The cage was then immersed in solvent in a jar for 3 days. The solvent was filtered off, and the remaining sample was dried for 2 days at room temperature. Complete drying was checked by a constant final weight. Bound rubber was calculated according to the following equation: ${ }^{11}$

$$
\operatorname{BdR}(\%)=\frac{W_{\mathrm{fg}-W_{\mathrm{t}}}\left(M_{\mathrm{f}} / M_{\mathrm{f}}+M_{\mathrm{r}}\right)}{W_{\mathrm{t}}\left(M_{\mathrm{r}} / M_{\mathrm{f}}+M_{\mathrm{r}}\right)} \times 100,
$$

where $\mathrm{BdR}$ is the bound rubber content; $W_{\mathrm{fg}}$ and $W_{\mathrm{t}}$ the weight of the sample after and before soaking, $M_{\mathrm{f}}$ the weight fraction of the filler in the compound and $M_{\mathrm{r}}$ the weight fraction of the rubber in the compound.

\subsection{Sorption experiment}

The EVA/HNTs samples for sorption experiments were punched out in the circular shape of diameter $1.9 \mathrm{~cm}$ and thickness $0.2 \mathrm{~cm}$ and dried in vacuum desiccators over anhydrous $\mathrm{CaCl}_{2}$ at room temperature for about $24 \mathrm{~h}$. The initial weight and thickness of the samples were measured before

Table 2. Formulation for EVA/HNTs nanocomposites (phr).

\begin{tabular}{lccc}
\hline & \multicolumn{3}{c}{ Ingredients } \\
\cline { 2 - 4 } EVA/HNTs sample & EVA & HNTs & DCP \\
\hline $\mathrm{EG}_{0}$ & 100 & 0 & 1.2 \\
$\mathrm{EH}_{1}$ & 100 & 2.5 & 1.2 \\
$\mathrm{EH}_{2}$ & 100 & 5 & 1.2 \\
$\mathrm{EH}_{3}$ & 100 & 7.5 & 1.2 \\
$\mathrm{EH}_{4}$ & 100 & 10 & 1.2 \\
\hline
\end{tabular}


sorption experiment. The sample was immersed in $20 \mathrm{ml}$ of solvents in closed diffusion bottles and kept at constant temperature by keeping in a thermostatically controlled heating oven. The weights of the swollen samples were measured at periodic intervals until equilibrium swelling is reached. The experiments were conducted at $30,40,50^{\circ} \mathrm{C}$. A possible sources of error in this measurement that arising during weighing since the sample has to be taken out from the solvent for weighing. The weighing is completed within 20$30 \mathrm{~s}$ to minimize the error due to evaporation of solvent. The results of sorption experiments were expressed as moles of solvent uptake by $100 \mathrm{~g}$ of polymer sample, $Q_{\mathrm{t}} \mathrm{mol} \%$

$$
Q_{\mathrm{t}}=\frac{\left(W_{\mathrm{t}}-W_{0} / W_{0}\right)}{M_{\mathrm{w}}} \times 100,
$$

where $W_{0}$ and $W_{\mathrm{t}}$ are the weights of the dry and swollen samples respectively and $M_{\mathrm{w}}$ the molar mass of the solvent.

\section{Results and discussion}

\subsection{Bound rubber content}

Bound rubber is the macroscopic result of rubber-filler physico-chemical interactions, and it reflects the reinforcing capabilities of the filler. For a given elastomer, the amount of bound rubber of fixed filler content depends on a number of factors, such as the surface area, structure and surface activity of the filler, the dispersion state, etc. Bound rubber measurement plays an important role in determining of surface activity and the degree of reinforcement of the filler. ${ }^{12}$ It is mostly accepted that the formation of bound rubber in a compound involves physical adsorption, chemisorptions and mechanical interaction, out of which chemisorption is considered as the crucial one. The adsorption of polymer molecules onto the filler surface leads to two phenomena, which are: the formation of bound rubber and a rubber shell on the filler surface. Many studies have been carried out on the mechanisms and factors affecting the formation of bound rubber. ${ }^{12-17}$ The variation of bound rubber content with filler loading has been studied with toluene as solvent. Table 3 shows the variation of the bound rubber content with the filler loading for EVA/HNTs nanocomposites. The bound rubber content has been found to be increased on HNTs loading up to $7.5 \mathrm{phr}$ and then decreases. The high percentage of bound rubber content is attributed to high surface area, high structure and high concentration of oxygen containing surface functional groups.

Table 3. Bound rubber content (\%).

\begin{tabular}{ll}
\hline EVA/HNTs sample & Bound rubber content (\%) \\
\hline $\mathrm{EH}_{1}$ & 47 \\
$\mathrm{EH}_{2}$ & 49.18 \\
$\mathrm{EH}_{3}$ & 51 \\
$\mathrm{EH}_{4}$ & 33 \\
\hline
\end{tabular}

\subsection{Sorption properties}

3.2a Effect of filler loading: Figure 1a-c shows the sorption curves of unfilled and HNTs-filled EVA nanocomposites in benzene, toluene and xylene at $30^{\circ} \mathrm{C}$, respectively. These figures show the mol\% of solvent uptake $\left(Q_{\mathrm{t}}\right)$ increases up to equilibrium absorption, where the mass of the absorbed solvent remained constant. The higher initial solvent absorption rates in polymers have been explained in terms of rapid cavitations, which expose a greater surface area, thus enhancing solvent percolation. ${ }^{18}$ Obasi et al ${ }^{19}$ studied the transport of toluene through linear low-density polyethylene/natural rubber blends found that the mass of toluene taken increased with time at the investigated temperatures until maximum absorption was reached. The mol\% of organic solvent uptake capacity of EVA/HNTs composite decreases as the HNTs filler loading in the matrix increases up to $7.5 \mathrm{phr}$ and above $7.5 \mathrm{phr}$ loading it increases. The HNTs loading restrains the long-range movements of the polymer molecules, but leave their local segmental mobility high.

3.2b Swelling ratio: Cured samples of dimension $30 \times$ $5 \times 2 \mathrm{~mm}^{3}$ were weighed and immersed in toluene for $72 \mathrm{~h}$ at $25^{\circ} \mathrm{C}$, then the samples weighed again to calculate percentage swelling ratio. The change in mass is calculated by the formulation

$$
\text { Swelling ratio }(\%)=\frac{W_{2}-W_{1}}{W_{1}} \times 100,
$$

where $W_{2}$ and $W_{1}$ are the mass of the samples after and before swelling in toluene.

Figure 2 shows the swelling percentage of EVA/HNTs nanocomposites as a function of HNTs loading. The swelling percentage decreased with the increase in HNTs loading up to $7.5 \mathrm{phr}$ then it increases for more than $7.5 \mathrm{phr}$ filler loading. Attempts have been made to explain this behaviour on the basis of the crosslink density between the EVA chains, ${ }^{20}$ which is discussed in the subsequent section.

3.2c Crosslink density: The crosslink density of samples has been estimated by applying the Flory-Rehner ${ }^{21}$ equation

$$
V=1 / 2 M_{\mathrm{c}}
$$

where $M_{\mathrm{c}}$ is the molar mass given by the equation

$$
\begin{aligned}
& M_{\mathrm{c}}=\left[-\rho_{\mathrm{p}} V_{\mathrm{s}} V_{\mathrm{r}}^{1 / 3}\right] /\left[\ln \left(1-V_{\mathrm{r}}\right)+V_{\mathrm{r}}+\chi V_{\mathrm{r}}^{2}\right] \\
& V_{\mathrm{r}}=1 / 1+Q_{\mathrm{m}}
\end{aligned}
$$

where $\rho$ is the density of the polymer, $\chi$ the polymer-solvent interaction parameter, $V_{\mathrm{s}}$ the molar volume of the solvent used, $V_{\mathrm{r}}$ the volume fraction of swollen rubber and $Q_{\mathrm{m}}$ the swelling weight of the EVA/HNTs composite in toluene.

Figure 3 shows the effect of HNTs loading on crosslink density and molar mass of the EVA/HNTs nanocomposites. The crosslink density of EVA/HNTs nanocomposites is increased with the addition of HNTs up to $7.5 \mathrm{phr}$, this is probably due to good interfacial and intertubular interactions 

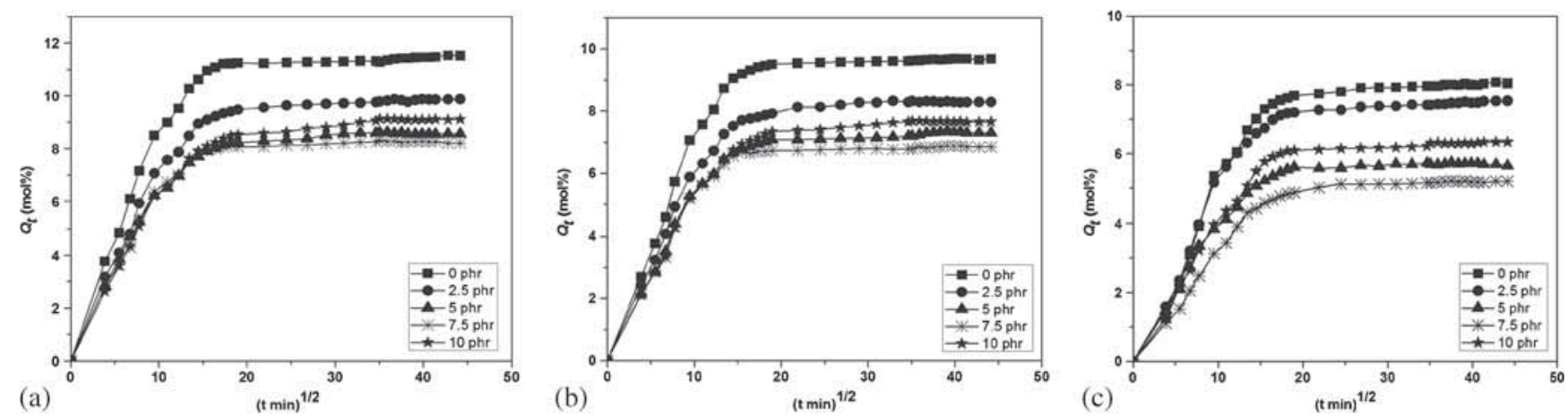

Figure 1. (a) Mol\% of benzene uptake by EVA/HNTs nanocomposites, (b) mol\% of toluene uptake by EVA/HNTs nanocomposites and (c) mol\% of xylene uptake by EVA/HNTs nanocomposites.

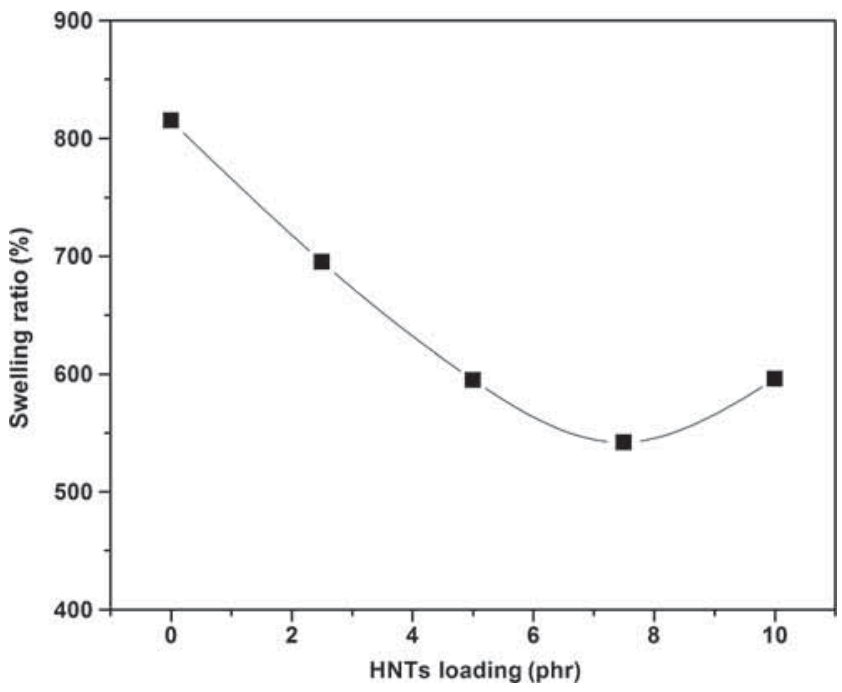

Figure 2. The effect of HNTs loading on the swelling \% of the EVA/HNTs nanocomposites.

of EVA and HNTs. Above $7.5 \mathrm{phr}$ HNTs loading it decreases, however, these values are found to be higher than the $\mathrm{EG}_{0}$ (0 phr HNTs). At a higher HNTs loading interaction between HNTs-HNTs predominates than HNTs-EVA interaction, which decreases the crosslink density and increases the molecular weight of the nanocomposites.

3.2d Swelling coefficient $(\alpha)$ : The extent of the swelling behaviour of the composites in different solvents is evaluated by swelling coefficients $(\alpha)$. Swelling coefficient $(\alpha)$ is calculated by the following equation:

$$
\alpha=\frac{\left(W_{2}-W_{1}\right)}{W_{1}} \times \rho_{\mathrm{s}}^{-1}
$$

where $W_{1}$ and $W_{2}$ are the weights of the sample before swelling and at equilibrium swelling, respectively, and $\rho_{\mathrm{s}}$ the density of the solvent. The swelling coefficient values of unfilled and filled EVA/HNTs nanocompsites are given in table 4 . Like swelling ratio (\%) as given in figure 2 , the

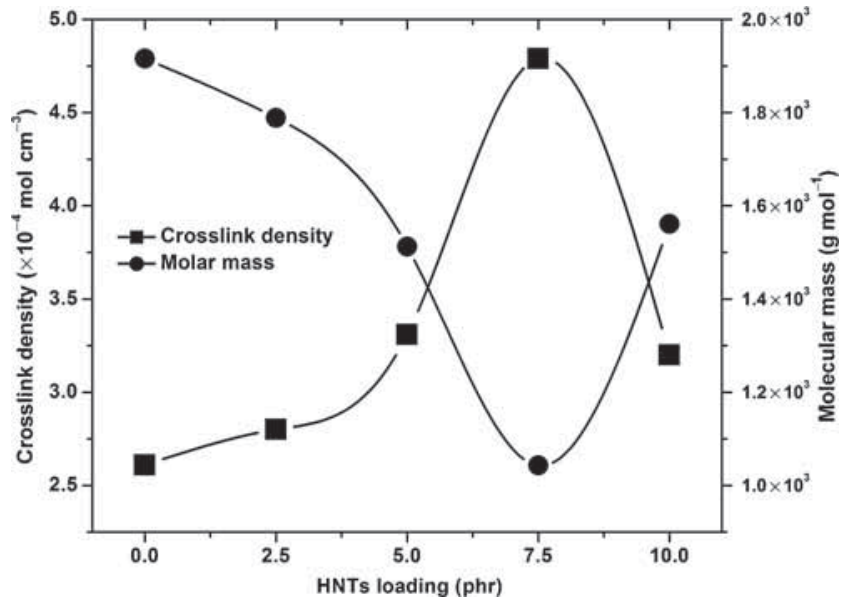

Figure 3. The effect of HNTs loading on the crosslink density and molar mass of the EVA/HNTs nanocomposites.

Table 4. Values of swelling coefficient $(\alpha)$.

\begin{tabular}{|c|c|c|c|c|}
\hline \multirow{2}{*}{$\begin{array}{l}\text { EVA/HNTs } \\
\text { sample }\end{array}$} & \multirow{2}{*}{$\begin{array}{l}\text { Filler loading } \\
\text { (phr) }\end{array}$} & \multicolumn{3}{|c|}{ Swelling coefficient $(\alpha)$} \\
\hline & & Benzene & Toluene & Xylene \\
\hline $\mathrm{EG}_{0}$ & 0 & 10.27 & 9.40 & 9.10 \\
\hline $\mathrm{EH}_{1}$ & 2.5 & 8.79 & 8.1 & 8.03 \\
\hline $\mathrm{EH}_{2}$ & 5 & 7.60 & 6.87 & 6.52 \\
\hline $\mathrm{EH}_{3}$ & 7.5 & 7.54 & 6.25 & 6.12 \\
\hline $\mathrm{EH}_{4}$ & 10 & 8.09 & 6.87 & 6.51 \\
\hline
\end{tabular}

swelling coefficient $(\alpha)$ values are found to be decreasing with the increase in HNTs content up to $7.5 \mathrm{phr}$ and then increases above $7.5 \mathrm{phr}$ filler loadings. However, all the values of swelling coefficient $(\alpha)$ of the composites are found to be lower than unfilled composites. This can be explained on the basis of the strong interaction between polymer segments and the HNTs filler surface, which decreases the polymer chain mobility and solvent uptake capacity. Also, as the molecular size/mass of the solvent increases from benzene to xylene, as expected, decrease in swelling coefficient values is observed for a given EVA/HNTs nanocomposite. This may be due to decrease in sorption and density of the solvent. 
3.2e Sorption coefficient $(S)$ : Sorption is a surface property which can indicate the nature of solvent sorbed into a polymer/or polymer composite. Table 5 lists the values of sorption coefficient $(S)$ or solubility of different composites obtained as grams of solvent (benzene, toluene and xylene) sorbed per gram of EVA/HNTs composite. It is observed that the sorption coefficient $(S)$ decreases with the increase in HNTs content up to $7.5 \mathrm{phr}$ at given temperature and for each benzene, toluene and xylene solvent, then it decreases above 7.5 phr HNTs loading. The sorption coefficient values were found to be highest for the solvent benzene, followed by toluene, and then xylene for a given temperature. As the temperature is increased from 30 to $50^{\circ} \mathrm{C}$ the sorption coefficient also increases, which is in agreement with published literature by Johnsons and Thomas ${ }^{22}$ and Igwe et $a l,{ }^{23}$ where it reported that the sorption coefficient increases with the increases in sorption temperature.

3.2f Diffusion coefficient $(D)$ : Diffusion coefficient is a kinetic parameter which can be related to the polymer segmental mobility, solvent nature and different crosslinks present in a polymer matrix. The diffusion coefficient of a polymeric material immersed in a given solvent can be calculated as follows: ${ }^{24}$

$$
\frac{Q_{t}}{Q_{\infty}}=1-\sum_{n=0}^{\infty}\left[\frac{8}{(2 n+1)^{2} \pi^{2}}\right] \mathrm{e}^{-(2 n+1)^{2} \pi^{2} D t / h^{2}},
$$

where $Q_{t}$ and $Q_{\infty}$ are the mol\% uptake at time $t$ and at equilibrium respectively, $n$ an integer, $D$ the diffusion coefficient, ' $t$ ' the time and ' $h$ ' the initial thickness of the polymer sample. While deriving equation (8) the thickness $(h)$ of the polymer sample is assumed to remain constant during the diffusion process. ${ }^{24}$ The thickness of the sample increases,

Table 5. Sorption coefficient $(S)$ values of EVA/HNTs composites in benzene, toluene and xylene.

\begin{tabular}{ccccc}
\hline & & \multicolumn{3}{c}{ Sorption coefficient $(S)$} \\
\cline { 3 - 5 } Solvent & $\begin{array}{c}\text { Filler content } \\
(\mathrm{phr})\end{array}$ & $303 \mathrm{~K}$ & $313 \mathrm{~K}$ & $323 \mathrm{~K}$ \\
\hline Benzene & 0 & 9.03 & 9.23 & 9.35 \\
& 2.5 & 7.72 & 7.89 & 7.97 \\
& 5 & 6.68 & 6.73 & 6.94 \\
& 7.5 & 6.63 & 6.69 & 6.81 \\
Toluene & 10 & 7.15 & 7.21 & 7.26 \\
& 0 & & & \\
& 2.5 & 7.89 & 9.20 & 8.90 \\
& 5 & 6.63 & 6.74 & 7.85 \\
& 7.5 & 6.60 & 6.31 & 6.53 \\
Xylene & 10 & 7.10 & 7.20 & 7.22 \\
& & & & \\
& 0 & 8.82 & 8.73 & 8.70 \\
& 2.5 & 7.13 & 7.68 & 7.72 \\
& 5 & 6.20 & 6.19 & 6.11 \\
& 7.5 & 6.00 & 5.29 & 5.88 \\
& 10 & 6.56 & 6.73 & 6.84 \\
\hline
\end{tabular}

in reality, as the solvent molecules enter into the polymer sample. Under such circumstance equation (8) can still be used by taking a fixed frame of reference with respect to the polymer sample.

This equation can be solved readily, an instructive to examine the short time limiting as:

$$
\frac{Q_{t}}{Q_{\infty}}=\left[4 / \pi^{1 / 2}\right]\left[D t / h^{2}\right]^{1 / 2} .
$$

The plot of $Q_{t}$ vs. $\sqrt{t}$ is initially linear. Hence $D$ can be calculated from the rearrangement equation (9) as

$$
D=\pi\left(\frac{h \theta}{4 Q_{\infty}}\right)^{2},
$$

where $h$ is the sample thickness, $\theta$ the slope of the initial linear portion of the sorption curves before the attainment of the $50 \%$ equilibrium uptake and $Q_{\infty}$ the equilibrium sorption value.

Table 6 shows that $D$ values increases with the decrease in the molecular mass of the aromatic solvents used. This trend of diffusion coefficient is in agreement with the article by Anil Kumar et $a .^{25}$ The decease in value of $D$ with the increase in molar mass and dipole moment and decreasing in density and solubility parameter of the aromatic solvents used as shown in table 1 . The solubility parameter is an important factor, which affects the sorption of polymers in solvent. The polymers and the solvents dissolve if their solubility parameters are equal. The present study shows a dependence of diffusivity on the molecular mass of solvents. Figure 4 shows diffusion co-efficient decreases with the increase in the number of carbon atoms of the penetrant which is in agreement to the report of authors. ${ }^{22,26}$ Diffusivity in a given polymer system may vary from one polymer system to another. The diffusion coefficient increases with increase in sorption temperature for each solvent which is an agreement with Johnson and Thomas, ${ }^{22}$ who reported that the $D$-value increases with increase in temperature. The effect of temperature may be due to the defacillation of diffusing molecules at the higher thermal energies by the increase of temperature.

The diffusion coefficient of EVA/HNTs nanocomposites also decreases with increase in HNTs content up to $7.5 \mathrm{phr}$ and above it increases. The diffusivity depends on the free volume within the polymer and the polymer chain segmental mobility.

3.2g Permeability coefficient $(P)$ : The permeability or permeation coefficient $(P)$ of a penetrant in a polymer membrane depends on the diffusivity as well as solubility or sorption of the penetrant in the polymer membrane. The permeability coefficient $(P)$ of the organic solvents in the EVA/HNTs composites was obtained using the following expression: ${ }^{27}$

$$
P=D \cdot S
$$


Table 6. Diffusion coefficient $(D)$ and permeability coefficient $(P)$.

\begin{tabular}{|c|c|c|c|c|c|c|c|}
\hline \multirow[b]{2}{*}{ Solvent } & \multirow{2}{*}{$\begin{array}{l}\text { Filler content } \\
\quad(\mathrm{phr})\end{array}$} & \multicolumn{3}{|c|}{$D \times 10^{-7}\left(\mathrm{~cm}^{2} \mathrm{~s}^{-1}\right)$} & \multicolumn{3}{|c|}{$P \times 10^{-7}\left(\mathrm{~cm}^{2} \mathrm{~s}^{-1}\right)$} \\
\hline & & $303 \mathrm{~K}$ & $313 \mathrm{~K}$ & $323 \mathrm{~K}$ & $303 \mathrm{~K}$ & $313 \mathrm{~K}$ & $323 \mathrm{~K}$ \\
\hline \multirow[t]{5}{*}{ Benzene } & 0 & 4.19 & 4.57 & 4.67 & 37.83 & 42.18 & 43.66 \\
\hline & 2.5 & 3.99 & 4.41 & 4.98 & 30.80 & 34.79 & 39.69 \\
\hline & 5 & 3.84 & 4.40 & 5.08 & 25.65 & 29.61 & 35.25 \\
\hline & 7.5 & 3.81 & 4.02 & 4.88 & 25.26 & 26.89 & 23.23 \\
\hline & 10 & 3.95 & 4.05 & 4.10 & 28.24 & 29.20 & 29.76 \\
\hline \multirow[t]{5}{*}{ Toluene } & 0 & 4.04 & 4.02 & 3.97 & 35.91 & 36.98 & 35.33 \\
\hline & 2.5 & 3.88 & 4.04 & 4.12 & 29.64 & 31.22 & 32.34 \\
\hline & 5 & 3.75 & 3.79 & 3.96 & 24.86 & 24.40 & 25.85 \\
\hline & 7.5 & 3.74 & 3.78 & 3.89 & 24.68 & 23.85 & 24.85 \\
\hline & 10 & 3.86 & 3.90 & 3.95 & 27.40 & 28.08 & 28.51 \\
\hline \multirow[t]{5}{*}{ Xylene } & 0 & 4.03 & 3.83 & 3.84 & 35.54 & 33.43 & 33.40 \\
\hline & 2.5 & 3.75 & 3.87 & 3.96 & 26.73 & 29.72 & 30.57 \\
\hline & 5 & 3.61 & 3.76 & 3.80 & 22.38 & 23.27 & 23.21 \\
\hline & 7.5 & 3.56 & 3.77 & 3.81 & 21.36 & 19.94 & 22.40 \\
\hline & 10 & 3.67 & 3.85 & 3.89 & 24.07 & 25.91 & 26.60 \\
\hline
\end{tabular}

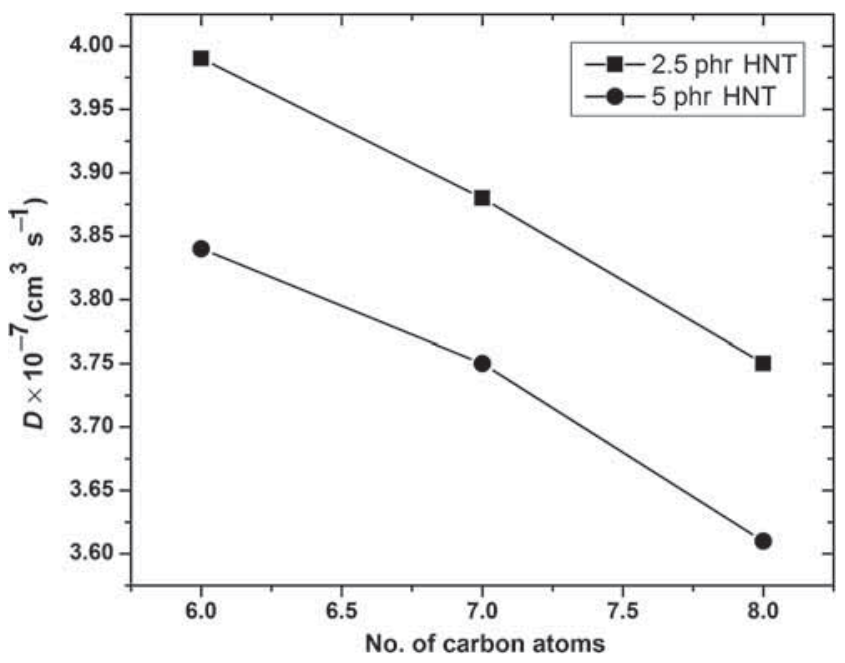

Figure 4. Variation of diffusivity $(D)$ on the number of carbon atoms of organic solvents in 2.5 and 5 phr HNTs loaded EVA/HNTs nanocomposites at $30^{\circ} \mathrm{C}$.

where $D$ is the diffusion coefficient and $S$ the sorption coefficient or solubility. The values of $P$ are given in table 6 . The value of $P$ increases with the increase in the sorption temperature. Mostly, high temperature makes more flexible polymer chains, facilitating the solvent permeability. This result is in agreement with Johnsons and Thomas ${ }^{22}$ and Unnikrishnan et $a l,{ }^{28}$ who reported that the permeation coefficient increases with the increase in the sorption temperature. The permeability coefficient was found to be decreasing with the molecular mass and dipole moment of the solvent, however Igwe et $a l^{23}$ found in his study that $P$-values increases with the increase in molar mass, molar volume and dipole moment of solvents. 3.2h Mode of transport: The mechanism of transport can be computed from the swelling data using the following: ${ }^{29}$

$$
\frac{Q_{t}}{Q_{\infty}}=k t^{n},
$$

where $Q_{t}$ and $\mathrm{Q}_{\infty}$ are the mol\% sorption at time ' $t$ ' and at equilibrium respectively, ' $k$ ' indicates the interaction between the penetrant and the polymer and ' $n$ ' represents the mode of transport. The roughness layer is small compared the thickness of the swollen polymer film, which in turn is much thicker than the dry film due to swelling in solvent. Therefore the influence of the film roughness on the mechanism of transport from the swelling data is minimized.

Taking $\log$ on both the sides, equation (12) becomes equation (13)

$$
\log \left(Q_{t} / Q_{\infty}\right)=\log k+n \log t .
$$

If the value of $n$ is 0.5 , it is the normal Fickian mode of transport, where the rate of polymer chain relaxation is higher compared to the diffusion rate of the penetrant. When $n=1$, the transport approaches non-Fickian behaviour, where chain relaxation is slower than the liquid diffusion. If the value of $n$ is in between 0.5 and 1 , the mode of transport is classified as anomalous. $k$ is a constant depending on the interaction between the polymer and solvent. The values of $n$ and $k$ are given in table 7. From the table it seems that the values of $n$ range between 0.344 and 0.60 for the three different solvents and temperatures, the mode of transport are close to Fickian. Dasan et al ${ }^{30}$ who studied the solvent transport through carbon black-filled EVA composites found the mode of transport to be anomalous. Similarly, Mathew et al $l^{31}$ who studied the transport of substituted benzene through natural rubber/polystyrene interpenetrating polymer network 
membranes found the mode of transport to be anomalous. The values of $n$ decrease whereas ' $k$ ' value increases with the increase in HNT filler loading in EVA/HNTs composites for a given solvent and temperature. The values of ' $n$ ' increase and the values of ' $k$ ' decreases with the increase in molar mass of the penetrant which show the decrease in polymersolvent interaction. The values of ' $n$ ' increase and ' $k$ ' values decrease with the increase in sorption temperature approaching the Fikian mode. For Fickian mode the rate of diffusion of penetrant molecule is much less than the relaxation rate of the polymer chains. Usually rubbers and semicrystalline polymers exhibit Fickian mode of transport. ${ }^{32}$

3.2i Effect of penetrant: The shape, size and polarity of solvents affect the sorption behaviour through polymer samples. Figure 5a-c shows the sorption curve for composites of benzene, toluene and xylene, respectively. The solvent uptake decreases as the size of the penetrant molecules increases from benzene to xylene. The low-molecular-weight benzene shows the highest uptake and the high-molecularweight xylene shows lowest uptake. This can be explained on the basis of free volume theory, ${ }^{6}$ according to which the diffusion rate of solvents through polymers depends on the rate with which the polymer chain segments exchange their positions with solvents. In case of composites the rate of exchange decreases with the increase in molecular size of solvents. Figure 6 shows that the $Q_{\infty}$ decreases with the increase in molar volume of the solvents for all EVA/HNTs composites.

3.2 $\mathrm{j}$ Thermodynamic parameters of sorption: The thermodynamic parameters for diffusion, $\Delta H$ and $\Delta S$ can be calculated using Van't Hoff's relation

$$
\log K_{\mathrm{s}}=\frac{\Delta S_{\mathrm{s}}}{2.303 R}-\frac{\Delta H_{\mathrm{s}}}{2.303 R T},
$$

Table 7. Parameters of mode of transport $n$ and $k$.

\begin{tabular}{|c|c|c|c|c|c|c|c|}
\hline \multirow[b]{2}{*}{ Solvent } & \multirow{2}{*}{$\begin{array}{l}\text { Filler content } \\
(\mathrm{phr})\end{array}$} & \multicolumn{3}{|c|}{$n$} & \multicolumn{3}{|c|}{$k\left(\min ^{-1}\right)$} \\
\hline & & $303 \mathrm{~K}$ & $313 \mathrm{~K}$ & $323 \mathrm{~K}$ & $303 \mathrm{~K}$ & $313 \mathrm{~K}$ & $323 \mathrm{~K}$ \\
\hline \multirow[t]{5}{*}{ Benzene } & 0 & 0.370 & 0.442 & 0.590 & 0.120 & 0.085 & 0.040 \\
\hline & 2.5 & 0.361 & 0.455 & 0.586 & 0.123 & 0.090 & 0.041 \\
\hline & 5 & 0.359 & 0.429 & 0.578 & 0.143 & 0.093 & 0.044 \\
\hline & 7.5 & 0.349 & 0.401 & 0.538 & 0.154 & 0.108 & 0.054 \\
\hline & 10 & 0.388 & 0.430 & 0.583 & 0.108 & 0.088 & 0.040 \\
\hline \multirow[t]{5}{*}{ Toluene } & 0 & 0.424 & 0.477 & 0.601 & 0.111 & 0.080 & 0.039 \\
\hline & 2.5 & 0.398 & 0.463 & 0.590 & 0.117 & 0.081 & 0.041 \\
\hline & 5 & 0.386 & 0.470 & 0.579 & 0.121 & 0.084 & 0.043 \\
\hline & 7.5 & 0.370 & 0.467 & 0.568 & 0.132 & 0.092 & 0.052 \\
\hline & 10 & 0.389 & 0.499 & 0.576 & 0.093 & 0.062 & 0.039 \\
\hline \multirow[t]{5}{*}{ Xylene } & 0 & 0.486 & 0.523 & 0.619 & 0.098 & 0.074 & 0.038 \\
\hline & 2.5 & 0.429 & 0.473 & 0.593 & 0.104 & 0.075 & 0.039 \\
\hline & 5 & 0.439 & 0.519 & 0.582 & 0.113 & 0.081 & 0.043 \\
\hline & 7.5 & 0.428 & 0.508 & 0.571 & 0.118 & 0.089 & 0.046 \\
\hline & 10 & 0.451 & 0.507 & 0.575 & 0.076 & 0.059 & 0.040 \\
\hline
\end{tabular}
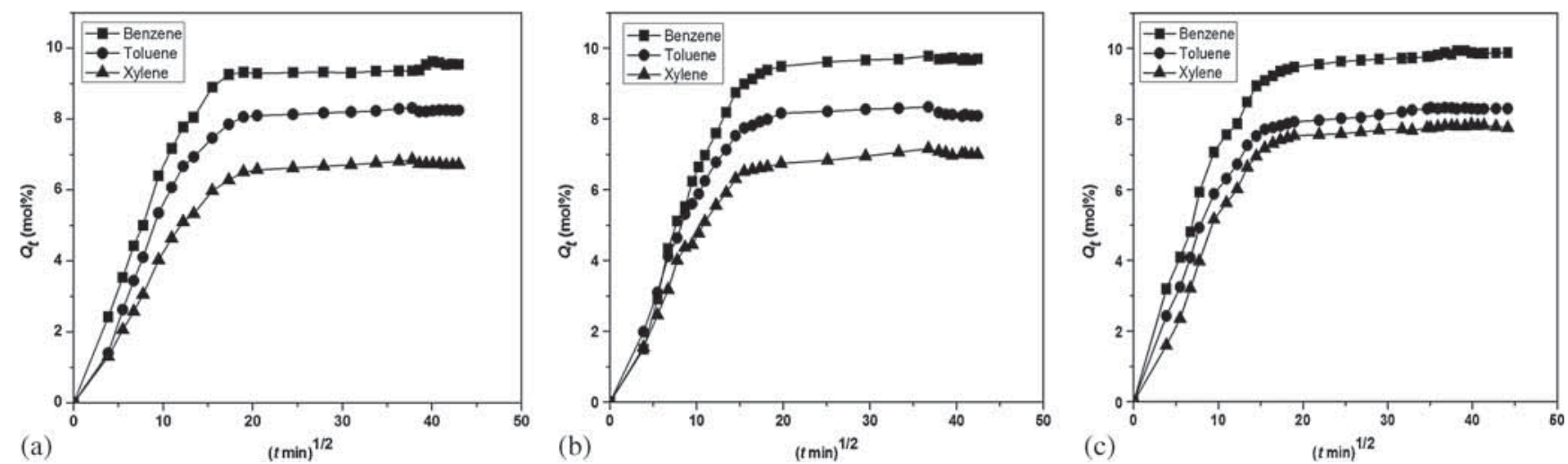

Figure 5. (a) Variation of mol\% uptake $\left(Q_{t}\right)$ with square root of time for the diffusion of benzene, toluene and xylene at $30^{\circ} \mathrm{C},(\mathbf{b}) 40^{\circ} \mathrm{C}$ and (c) $50^{\circ} \mathrm{C}$ of $2.5 \mathrm{phr}$ HNTs-loaded EVA nanocomposite. 


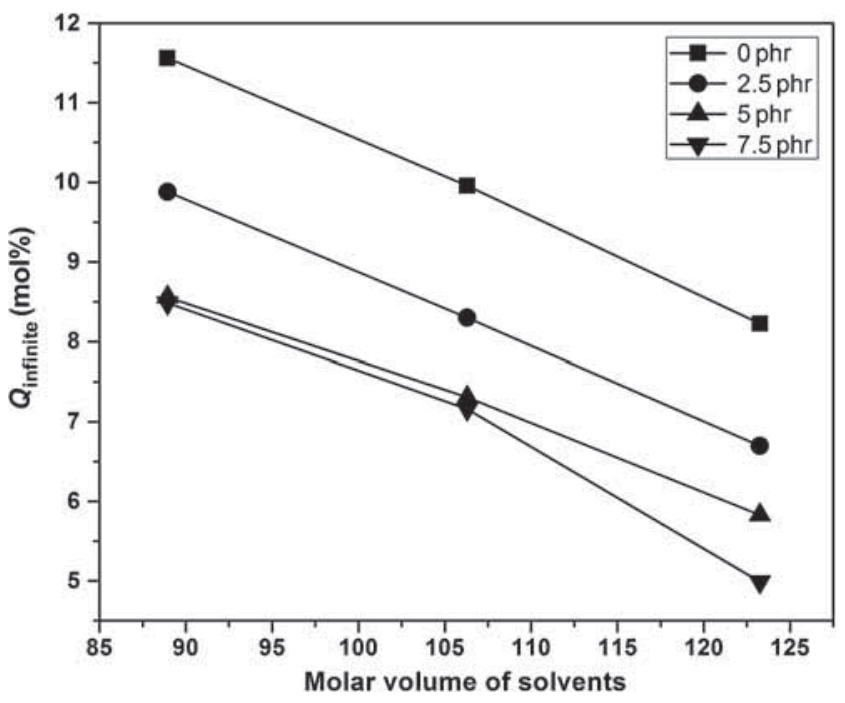

Figure 6. Variation of equilibrium uptake $\left(Q_{\infty}\right)$ with molar volume of the solvents at $30^{\circ} \mathrm{C}$ as a function of HNTs content in EVA matrix.

Table 8. Values of enthalpy of absorption, entropy of absorption and free energy of composites.

\begin{tabular}{ccccc}
\hline Solvent & $\begin{array}{c}\text { Filler content } \\
(\mathrm{phr})\end{array}$ & $\begin{array}{c}\Delta H_{\mathrm{S}} \\
\left(\mathrm{kJ} \mathrm{mol}^{-1}\right)\end{array}$ & $\begin{array}{c}\Delta S_{\mathrm{S}} \\
\left(\mathrm{J} \mathrm{mol}^{-1} \mathrm{~K}^{-1}\right)\end{array}$ & $\begin{array}{c}\Delta G \\
\left(\mathrm{~kJ} \mathrm{~mol}^{-1}\right)\end{array}$ \\
\hline Benzene & 0 & -2.13 & -25.16 & 5.49 \\
& 2.5 & -0.83 & -22.36 & 5.94 \\
& 5 & -1.75 & -26.65 & 6.32 \\
& 7.5 & -2.32 & -28.70 & 6.37 \\
Toluene & 10 & -4.17 & -28.67 & 4.51 \\
& 0 & -0.25 & -19.60 & 5.68 \\
& 2.5 & -5.91 & -39.11 & 5.94 \\
& 5 & -0.36 & -23.43 & 6.73 \\
& 7.5 & -0.32 & -23.39 & 6.76 \\
Xylene & 10 & -2.80 & -26.40 & 5.19 \\
& 0 & -0.91 & -24.35 & 6.46 \\
& 2.5 & -3.92 & -34.58 & 6.55 \\
& 5 & -1.29 & -27.78 & 7.12 \\
& 7.5 & -2.35 & -31.36 & 7.15 \\
& 10 & -3.33 & -31.61 & 6.24 \\
\hline
\end{tabular}

where $K_{\mathrm{s}}$ is the equilibrium sorption constant which is given by

$$
K_{\mathrm{s}}=\frac{\text { Number of moles of solvent sorbed at equilibrium }}{\text { Mass of the polymer sample }} .
$$

The values of $\Delta H_{\mathrm{s}}$ and $\Delta S_{\mathrm{s}}$ are obtained by the regression analysis of the plots of $\log K_{\mathrm{S}} v s .1 / T$.

The $\Delta H_{\mathrm{s}}$ and $\Delta S_{\mathrm{s}}$ values were found to be negative, the negative values of $\Delta H_{\mathrm{s}}$ indicate the exothermicity for the sorption process in agreement with Unikrishnan and Thomas. ${ }^{33}$ However, the negative values of $\Delta H_{\mathrm{s}}$ and $\Delta S_{\mathrm{s}}$ show no relationship to the filler content, molar mass and dipole moment of the solvent. The change in $\Delta G_{\mathrm{s}}$ for the aromatic solvents in the EVA/HNTs nanocomposite was obtained using the expression

$$
\Delta G_{\mathrm{s}}=\Delta H_{\mathrm{s}}-T \Delta S_{\mathrm{s}}
$$

where $T$ is the temperature in Kelvin. Table 8 lists the thermodynamic parameters of sorption for the aromatic solvent benzene, toluene and xylene. The $\Delta G_{\mathrm{s}}$ values were found to positive in all cases indicating the non-spontaneity of the solubility of EVA/HNTs composite in the organic solvents at $303 \mathrm{~K}$. According to Igwe, ${ }^{34}$ as the HNTs content in the composite increases the $\Delta \mathrm{G}_{\mathrm{s}}$ becomes more positive, indicating the increase in non-spontaneity irrespective of the nature of the solvent. As the molecular mass of the solvent is increased the $\Delta G_{\mathrm{s}}$ values also increases.

\section{Conclusions}

The transport behaviour of EVA/HNTs composites has been studied using three organic solvent benzene, toluene and xylene with temperature variation. The bound rubber content has been found to be increasing with HNTs loading up to $7.5 \mathrm{phr}$ and above $7.5 \mathrm{phr}$ loading decreasing trend is observed. Similarly, the mol\% of organic solvent uptake capacity of EVA/HNTs composite decreases as the HNTs filler loading in the matrix increases up to $7.5 \mathrm{phr}$ and above $7.5 \mathrm{phr}$ loading it increases. This is probably due to the HNTs loading in the EVA polymer restrain the longrange movements of the polymer molecules. Due to good interfacial and intertabular interactions of EVA and HNTs the swelling percentage decreases and the crosslink density increases with HNTs loading up to $7.5 \mathrm{phr}$. The swelling coefficient $(\alpha)$, sorption coefficient $(S)$, diffusion coefficient $(D)$ and permeability or permeation coefficient $(P)$ values were found to decrease with HNTs loading up to $7.5 \mathrm{phr}$. The sorption coefficient values were found to be highest for the solvent benzene, followed by toluene, and then xylene for a given temperature. As the temperature is increased from 30 to $50^{\circ} \mathrm{C}$ the sorption coefficient also increases. The transport behaviour study revealed that the value of ' $n$ ' increases and ' $k$ ' value decreases with the increase in sorption temperatures approaching the Fickian mode. As the HNT content in the composite increases the change in free energy $\left(\Delta G_{\mathrm{s}}\right)$ becomes more positive, indicating the increase non-spontaneity irrespective of the nature of the organic solvent.

\section{Acknowledgement}

We thank Lanxess India, for kindly supplying the LEVAPREN 450 used in this study. 


\section{References}

1. Landois-Garza J and Hotchkiss J H 1988 Food and packaging interactions (American Chemical Society Symposium Series: Washington)

2. Seymour R B 1990 Engineering polymer source book (New York: McGraw-Hill Publishing)

3. Huang R Y M 1991 Pervaporation membrane separation processes (New York: Elsevier)

4. Kulkarni P V, Rajur S B, Antich P, Aminabhavi T M and Aralaguppi M I 1990 J. Macromol. Sci. Rev. Macromol. Chem. Phy. 30441

5. Peppas N A 1987 Hydrogels in medicine and pharmacy (Boca Raton: CRC Press)

6. Stephen R, Joseph K, Oommen Z and Thomas S 2007 Compos. Sci. Technol. 671187

7. George S, Varghuse K T and Thomas S 2000 Polymer 41579

8. Liu M, Guo B, Du M and Jia D 2007 Appl. Phys. A 88391

9. Joussein E, Petit S, Churchman G J, Theng B K G, Righi D and Delvaux B 2005 Clay Miner. 40383

10. Levis S R and Deasy P B 2002 Int. J. Pharm. 243125

11. Leblanc J L and Hardy P 1991 Kautschuk Gummi Kunststoffe 441119

12. Choi S S 2002 Polym. Adv. Technol. 13466

13. Wolff S and Wang M J 1993 Carbon black reinforcement of elastomers. in 'Carbon Black: Science and Technology' (eds. J B Donnet, R C Bansal, M J Wang) Marcel Dekker New York, USA 289

14. Kraus G 1965 Reinforcement of elastomers (New York: Wiley Interscience)

15. Stickney P B and Falb R D 1964 Rubber Chem. Technol. 37 1299

16. Sircar A K and Voet A 1970 Rubber Chem. Technol. 43973
17. Wolff S, Wang M J and Tan E H 1993 Rubber Chem. Technol. 66163

18. Desai A B and Wilkes G L 1974 J. Polym. Sci. 46291

19. Obasi H C, Ogbobe O and Igwe I O 2009 Int. J. Polym. Sci. 20096 (Article ID 140682)

20. Munusamy Y, Ismail H and Mariatti M 2008 J. Rein. Plas. Com. 271925

21. Flory P J 1953 Principles of polymer chemistry (Ithaca: Cornell University Press)

22. Johnson T and Thomas S 2000 Polymer 417511

23. Igwe I O, Ewulonu C M and Igboanugo I 2006 J. Appl. Polym. Sci. 1021985

24. Crank J 1975 The mathematics of diffusion (Oxford: Oxford University Press)

25. Anil Kumar P V, Varghuse K T and Thomas S 2012 Ind. Eng. Chem. Res. $\mathbf{5 1} 6697$

26. Mathai A E, Singh R P and Thomas S 2002 J. Membr. Sci. 202 35

27. Kumnuantip C and Sombatsompop N 2003 Mater. Lett. 57 3167

28. Unnikrishnan G, Thomas S and Varghese S 1996 Polymer 37 2687

29. Aminabhavi T M and Phayde H T S 1995 J. Appl. Polym. Sci. 551335

30. Dasan K P, Unnikrishnan G and Purushothaman E 2008 Express Polym. Lett. 2382

31. Mathew A P, Packirisamy S, Kumaran M G and Thomas S 2002 Polymer 254935

32. Hopfenberg H B and Paul D R 1976 In: Paul D R editor Polymer blends (New York: Academic Press)

33. Unnikrishnan G and Thomas S 1998 Polymer 393933

34. Igwe I O 2007 J. Appl. Polym. Sci. 1043849 